\title{
Acute tolerance to the motor impairment effects of ethanol
}

\author{
BEVERLY M. KULIG \\ Department of Physiology, University of Leiden, Leiden, The Netherlands
}

\begin{abstract}
Rats were trained to avoid electric shock by running treadmill-fashion along a moving belt. When the animals were consistently performing at a $95 \%$ avoidance level, the effects of saline and $1.5,2.0$, and $2.5 \mathrm{~g} / \mathrm{kg}$ ethanol on motor performance were assessed in three 2 -min trials $23 \mathrm{~min}$ following IP administration. Results indicated a strong relationship between plasma alcohol concentration and the mean time off the belt for the three trials. Further, the technique differentiated a dose-dependent impairment in responding. In addition, the results indicated that the motor impairment effects diminished for all dose levels over the 7-min test period. It is unlikely that the improved performance across the three trials is due to changes in metabolism or increased duration of exposure to the drug. The data suggest that the moving belt test is sensitive to practice effects and that a behavioral augmentation to the motor impairment effects of ethanol can occur within several minutes.
\end{abstract}

Various methods have been used to assess the effects of alcohol and the development of tolerance on motor function and coordination in animals (e.g., Arvola, Sammalisto, \& Wallgren, 1958; Dunham \& Miya, 1957; Newman \& Card, 1937). Recently, Gibbins, Kalant, and LeBlanc (1968) described a technique whereby rats trained to stay on a continuous motor-driven belt running over an electrified grid showed a dose-dependent impairment of learned performance when given ethanol at moderate dose levels. Using the moving-belt test, these authors subsequently demonstrated the development of tolerance following chronic ethanol administration (LeBlanc, Kalant, \& Gibbins, 1969) and an ethanol-induced tolerance to homologous alcohols (LeBlanc \& Kalant, 1975). Further, a study relating the degree of motor impairment to brain alcohol concentrations (LeBlanc, Kalant, \& Gibbins, 1975) indicated a reduced impairment for a given alcohol concentration on the falling vs. the rising portion of the blood alcohol curve.

The present experiment was designed to replicate the dose-dependent effects of ethanol using this technique as a starting point for further investigations of functional tolerance to drugs which produce impairment of learned motor behavior. In addition, earlier studies utilizing the moving-belt technique reported no change in performance across trials

These data were collected while the author was a Research Associate at the Alcohol and Drug Research Institute, Tennessee Psychiatric Hospital and the University of Tennessee Medical Units, Memphis, Tennessee. This work was supported by a grant from the State of Tennessee Department of Mental Health. The author wishes to thank Ms. Katherine V. Tullis for her excellent technical assistance, Mr. John Simpson for the chromatographic analyses, and the staff of the Alcohol and Drug Research Institute for their support and encouragement.
(Gibbins et al., 1968), however, subsequent experiments (e.g., LeBlanc \& Kalant, 1975), incorporating modifications of the original test, reported alcoholinduced impairment as the maximum time off belt during any single trial in a series of two-minute trials, a finding which suggests a trial-by-trial variation. Thus, the data were examined to determine whether there was a progressive improvement in performance over three 2-min trials under control and drug conditions.

\section{METHOD}

\section{Subjects}

Thirteen naive male Sprague-Dawley rats (Holtzman Co., Madison, Wisconsin), weighing $194-200 \mathrm{~g}$, served as subjects. Animals were housed 3-4 per cage and received Purina Lab Chow and water ad lib except where noted. Animals were maintained on a $0600-1800$-h light-dark cycle and all drug testing was performed between 1200 and $1600 \mathrm{~h}$. Two rats failed to achieve stable treadmill performance prior to drug treatment and were discarded from the experiment.

\footnotetext{
Apparatus

The apparatus consisted of a Lucite compartment $(54 \times 29 \times$ $33 \mathrm{~cm}$ high) with a grid floor comprising stainless steel rods over which stretched a continuous loop of nylon webbing. The nylon belt $(5.6 \mathrm{~cm}$ wide) extended outside the compartment over two wooden cylinders, leaving $53 \mathrm{~cm}$ of the belt exposed in the compartment. One of the two cylinders was rotated by a $115-\mathrm{V}$ 1/12-hp motor such that the belt moved at a constant speed of $7 \mathrm{~cm} / \mathrm{sec}$. Stainless steel staples in the belt made contact with a supporting metal strip which was attached to the first rod in the grid floor. A Lucite strip beneath the metal strip insulated the nylon belt from the rest of the grid floor. A constant current source $(400 \mathrm{~V} \mathrm{dc})$ delivered scrambled shock $(300 \mu \mathrm{A})$ to the grid floor. The apparatus was constructed in such a way that an animal was forced to run treadmill-fashion completely on the belt to avoid the shocked grid. An animal was considered off the belt if one or more paws touched the grid floor. Time off belt was noted by visual observation and recorded by means of a stopwatch.
} 


\section{Procedure}

All animals were trained to avoid shock by remaining on the belt. Each training session consisted of three 2-min trials spaced $30 \mathrm{sec}$ apart. The animal was placed on the moving belt and after a 2 -sec delay the grid was electrified. At the end of 2 min, the animal was removed and kept in a cage during the intertrial interval. The behavioral testing and plasma alcohol determinations were performed without knowledge of the dose given.

When all animals were responding reliably at a $95 \%$ avoidance level, the effects of saline and three doses of ethanol were measured. On all injection days, the animals were food-deprived for approximately $4 \mathrm{~h}$. Each test session consisted of three 2-min trials spaced $30 \mathrm{sec}$ apart and began $23 \mathrm{~min}$ following injection. On Day 1, all animals received a volume of saline (IP) equivalent to a $2.0-\mathrm{g} / \mathrm{kg}$ dose of a $20 \%(\mathrm{w} / \mathrm{v})$ ethanol solution, and the effects of saline on treadmill performance were assessed. The animals were then randomly assigned to three groups, and on each of three subsequent test days were given an IP injection of a different dose of $20 \%(\mathrm{w} / \mathrm{v})$ ethanol in normal saline of $1.5,2.0$, or $2.5 \mathrm{~g} / \mathrm{kg}$, such that all animals received each dose once in a counterbalanced fashion. On the 5th test day, saline was again administered to all subjects. The test sessions were separated by either 1 or 2 days.

Blood plasma alcohol determinations were made on each drug test day. Immediately after the completion of the third trial, a blood sample was taken from the tail vein and the plasma alcohol concentration was analyzed by a Perkin-Elmer Model 990 gas chromatograph equipped with a flame ionization detector using a method previously described (Sargent, Simpson, \& Beard, 1974). On the 2nd alcohol test day, an error was made in the addition of the internal standard to some of the samples and these samples were discarded. Thus, the relationship between plasma alcohol concentration and treadmill performance was based on 27 pairs of scores.

\section{RESULTS}

Analysis of the relationship between plasma alcohol concentration and mean time off belt for the

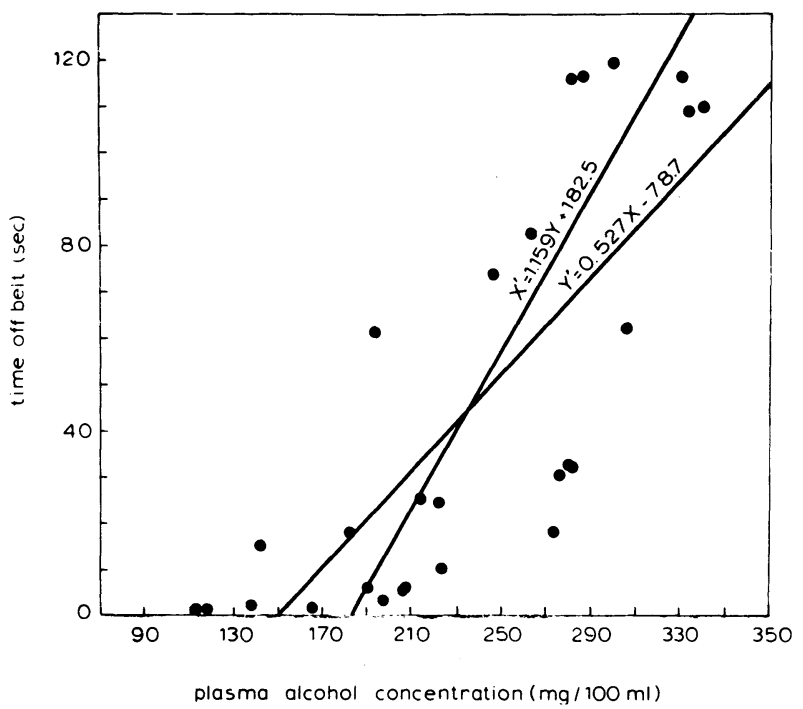

Figure 1. The relationship between plasma alcohol concentration and performance on the moving belt test. The regression of time off belt on plasma alcohol concentration is shown by $x^{1}=1.159 y+182.5$ and of plasma alcohol concentration on time off belt by $y^{\prime}=0.527 x-78.7$, where $x^{1}$ equals predicted time off belt, $x$ equals observed time off belt, $y^{1}$ equals predicted plasma alcohol level, and y equals observed plasma alcohol level.

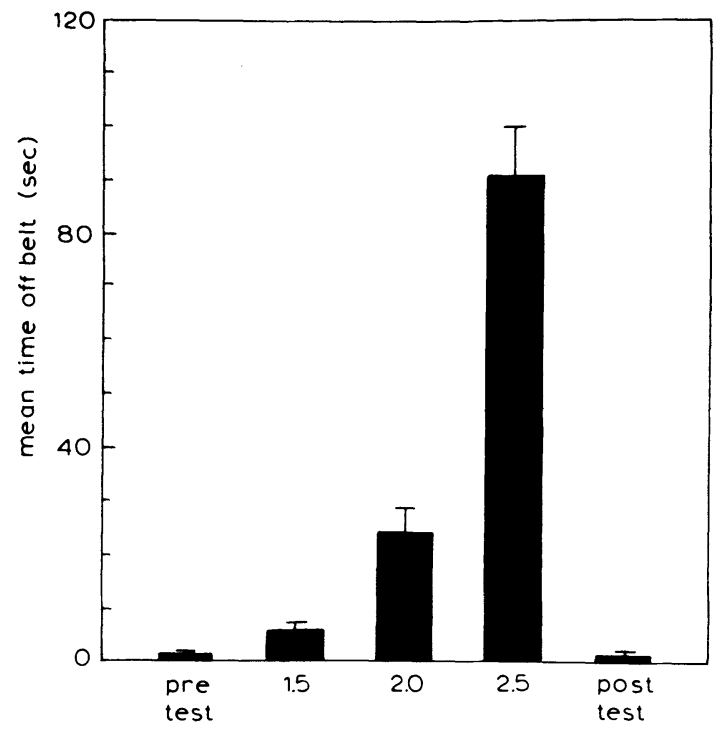

Figure 2. The effects of saline and different doses of ethanol $(\mathrm{g} / \mathrm{kg})$ on performance in the moving belt test.

three trials (Figure 1) revealed a significant correlation $(r=.78, t=6.26$, df $=25, p<.001)$. A linear regression analysis of the data showed the plasma alcohol concentration on the performance variable to be $\mathrm{y}^{1}=.53 \mathrm{x}-78.70$. In predicting the blood plasma alcohol level from the response, it was found that the alcohol level equals $1.59 \times$ response +182.50 .

In addition to the relationship between plasma alcohol concentration and performance, the data for the different dose levels was also compared (Figure 2). Pairwise comparisons of the mean time off belt for the different dose levels using a paired t test (two-tailed) revealed that the mean time off belt was significantly greater for the $2.0-\mathrm{g} / \mathrm{kg}$ group compared with that of the $1.5 \mathrm{-g} / \mathrm{kg}$ group $(\mathrm{t}=3.90$, $\mathrm{df}=10, \mathrm{p}<.01)$ and the $2.5 \mathrm{-g} / \mathrm{kg}$ group was significantly different from the $2.0-\mathrm{g} / \mathrm{kg}$ group $(\mathrm{t}=5.84$, $\mathrm{df}=10, \mathrm{p}<.001)$. Analysis of the performance on the saline pretest vs. saline posttest revealed no significant changes $(t=.58, \mathrm{df}=10)$. In addition, the performance at 2.0 and $2.5 \mathrm{~g} / \mathrm{kg}$ was significantly different from the saline pretest $(\mathrm{t}=4.78, \mathrm{df}=$ $10, \mathrm{p}<.001 ; \mathrm{t}=9.41, \mathrm{df}=10, \mathrm{p}<.001$, respectively). However, the mean time off belt for three trials at $1.5 \mathrm{~g} / \mathrm{kg}$ was not significantly different compared with the saline pretest $(t=.91$, $\mathrm{df}=10)$.

The data were also inspected to determine whether performance at different dose levels changed over the three trials (Figure 3). A Treatments by Subjects analysis of variance revealed that at each dose level tested the time off belt declined over trials $(1.5 \mathrm{~g} / \mathrm{kg}$, $\mathrm{F}=10.71, \mathrm{df}=2 / 20, \mathrm{p}<.001 ; 2.0 \mathrm{~g} / \mathrm{kg}, \mathrm{F}=22.51$, $\mathrm{df}=2 / 20, \mathrm{p}<.001 ; 2.5 \mathrm{~g} / \mathrm{kg}, \mathrm{F}=14.49, \mathrm{df}=$ $2 / 20, p<.001)$. Pairwise comparisons using a 


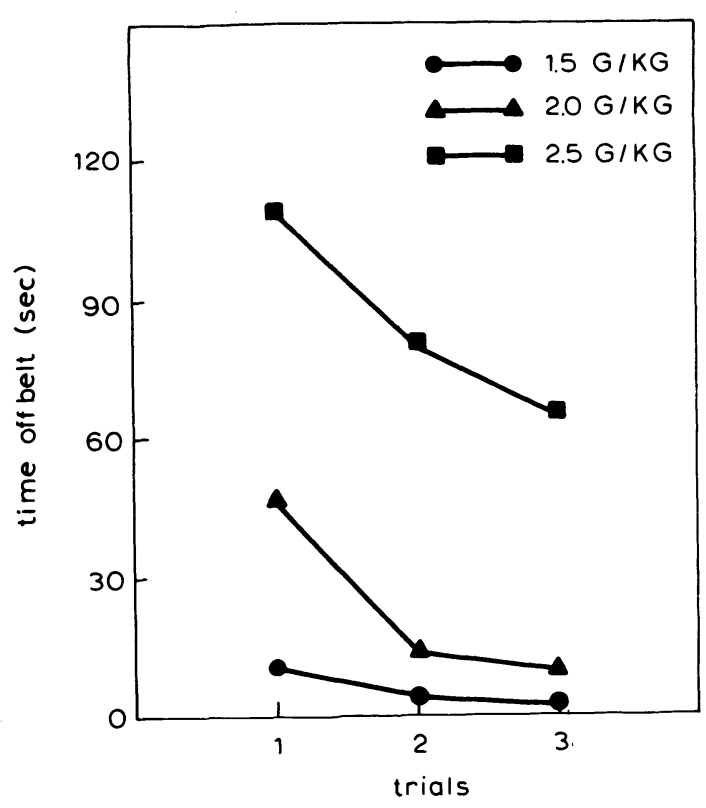

Figure 3. Changes in motor performance within a single test session for different doses of ethanol.

paired $t$ test between the trials for each dose level revealed that for the $1.5-\mathrm{g} / \mathrm{kg}$ dose, Trial 1 differed from Trial $2(\mathrm{t}=3.07, \mathrm{df}=10, \mathrm{p}<.02)$ and Trial 2 differed from Trial $3(\mathrm{t}=2.48$, df $=10, \mathrm{p}<.05)$. Trial 1 also differed from Trial 2 for the $2.0-\mathrm{g} / \mathrm{kg}$ dose $(\mathrm{t}=4.28, \mathrm{df}=10, \mathrm{p}<.002)$ and the $2.5-\mathrm{g} / \mathrm{kg}$ dose $(\mathrm{t}=2.98, \mathrm{df}=10, \mathrm{p}<.02)$. Trial 2 vs. Trial 3 performance for the $2.0-\mathrm{g} / \mathrm{kg}$ dose was not significant $(\mathrm{p}>.1)$ but was significant for the $2.5-\mathrm{g} / \mathrm{kg}$ dose $(t=3.01, d f=10, p<.02)$. Analysis of variance of performance over trials for the saline pretest and the saline posttest revealed no significant differences $(F=2.96, \mathrm{df}=2 / 20$, and $F=2.05$, df $=2 / 20$, respectively). The mean time off belt in seconds on the saline pretest for the three trials was $0.73,0.73$, and 2.45, and for the posttest, $0.55,1.09$, and 1.82 , respectively.

\section{DISCUSSION}

The present experiment replicates previously reported results that the moving belt test provides a reliable means of assessing dose-dependent effects of ethanol at moderate dose levels. There was a strong relationship between plasma ethanol levels and mean time off belt when the plasma alcohol concentrations ranged between 150 and $340 \mathrm{mg} \%$. Moreover, the test was sensitive to $0.5-\mathrm{g}$ increments in dosage.

However, in contrast to previous findings, the present experiment indicated that for all dose levels tested, rats showed a progressive improvement over the three trials. Even for the lowest dose group, performance on Trial 1 following $1.5 \mathrm{~g} / \mathrm{kg}$ ethanol compared to Trial 1 performance on the saline pretest was significantly impaired $(t=3.69, \mathrm{df}=10, \mathrm{p}<.005)$ while Trial 3 responding during ethanol and saline tests were not significantly different. Differences in belt speed, the use of scrambled shock at a lower intensity, and other procedural variables most likely account for the discrepancy between these data and those of the earliest reports using this technique (e.g., Gibbins et al., 1968). Clearly, a more detailed analysis of the variables contributing to the acquisition and maintenance of treadmill performance is warranted before a conclusion can be reached.

An explanation of the finding of improved performance over trials in terms of changes in blood or brain concentrations of ethanol can be ruled out on the basis of what is known regarding the metabolism of the alcohols. Ethanol comes into rapid equilibrium with tissues and is metabolized at the rate of $17-30 \mathrm{mg} / 100 \mathrm{ml} / \mathrm{h}$ (Kalant, 1971). These data are not consonant with an explanation based on diminished drug concentration, but rather suggest that the moving belt test is capable of discriminating rapidly changing behavioral processes which occur in a drug state.

It is possible that the improved performance is a practice effect whereby the animals learned to overcome the functional deficit produced by the presence of the drug, i.e., that the improvement over trials is aspecific with respect to a given compound or class of compounds, but is, rather, a function of the degree of drug-induced impairment. It may prove fruitful in future investigations to examine whether a number of compounds which produce equivalent impairment on the moving belt test, but which differ along such parameters as chemical structure, abuse potential, or addiction potential exhibit similar acute tolerance profiles. Further research, at both the biochemical and behavioral level, is needed to elucidate the role of behavioral processes in acute and chronic tolerance development and their relationship with the more classical pharmacological concepts of tolerance and addiction.

\section{REFERENCES}

Arvola, A., Sammalisto, L., \& Wallgren, H. A test for level of alcohol intoxication in the rat. Quarterly Journal of Alcohol Studies, 1958, 19, 563-572.

Dunham, N. W., \& Mrya, T. S. A note on a simple apparatus for detecting neurological deficit in rats and mice. Journal of the American Pharmaceutical Association, 1957, 46, 208-209.

Gibbins, R. J., Kalant, H., \& LeBlanc, A. E. A technique for accurate measurement of moderate degrees of alcohol intoxication in small animals. Journal of Pharmacology and Experimental Therapeutics, 1968, 159, 236-242.

Kalant, H. Absorption, distribution and elimination of alcohols. In B. Kissin \& M. M. Begleiter (Eds.), The biology of alcoholism (Vol. 1). Physiology \& biochemistry (Chap. 1). New York: Plenum, 1971.

LeBlanc, A. E., \& Kalant, H. Ethanol-induced tolerance to several homologous alcohols in the rat. Toxicology and Applied Pharmacology, 1975, 32, 123-128. 
LeBlanc, A. E., Kalant, H., \& Gibbins, R. J. Acute tolerance to ethanol in the rat. Psychopharmacologia (Berl.), 1975, 41, 43-46.

LeBlanc, A. E., Kalant, H., Gibbins, R. J., \& Berman, N. D. Acquisition and loss of tolerance to ethanol by the rat. Journal of Pharmacology and Experimental Therapeutics, 1969, 168, 244-250.

Newman, H., \& CARD, J. Duration of acquired tolerance to ethyl alcohol. Journal of Pharmacology and Experimental Therapeutics, 1937, 59, 249-252.
Sargent, W. Q., Simpson, J. R., \& Beard, J. D. The effect of acute and chronic alcohol administration on renal hemodynamics and monovalent ion excretion. Journal of Pharmacology and Experimental Therapeutics, 1974, 188, 461-471.

(Received for publication February 24, 1976; revision accepted August 19, 1976.) 